\title{
Involving Nepali academics in health research
}

\author{
Neupane D1, van Teijlingen $E^{2}$, Khanal V³ , Mishra SR ${ }^{4}$, Kallestrup P5 \\ ${ }^{2}$ Edwin van Teijlingen, Center for Midwifery, Maternal and Perinatal Health, School of Health and Social Care, Bournemouth University \\ ${ }^{3}$ Vishnu Khanal, PhD Scholar, School of Public Health, Curtin University, Australia \\ ${ }^{4}$ Shiva Raj Mishra, BPH, People's Health Movement, Nepal \\ ${ }^{5}$ Per Kallestrup, MD, PhD, Associate Professor, Center for Global Health, Department of Public Health, Aarhus University, Denmark
}

\begin{abstract}
Many academics from Nepal do not involve in research activities. There are several factors hindering the involvement such as inadequate human resources and lack of financial resources. Despite limited human and financial resources, we believe it is still possible to attract many Nepali academics in health research. This paper purposes some ideas to increase involvement of Nepali academics in health research.
\end{abstract}

\section{Background}

In a world dominated by globalization and knowledge exchange conducting research and academic publishing has become increasingly important. In this light it is important to report the findings of research conducted in Nepal as it may be relevant and useful in Nigeria or Nicaragua. However, there is also the desire among researchers to find out new things and enhance their own knowledge, progress their careers, and generally communicate their research to fellow academics, practitioners, policy-makers and the wider society. $(1,2)$ We know research is important in generating evidence for planning and policy making. (3) Implementation of public health programmes often lacks local evidence in many developing countries. (4) Many such initiatives are suggested by donors who often base their interventions on either research findings from other countries or their judgments and ideologies. (5)

So, it is important to increase our efforts and generate more scientific evidence from within low-income countries. Building indigenous research capacity will enable local scientists to translate results of studies into their own national settings. Eventually such studies will increase the global knowledge base about the particular health problems and contribute to finding appropriate solutions. $(6,7)$ To date, strengthening research capacity in developing regions remains one of the world's unmet challenges. (7)

Many perceive that the barriers to health research capacity in Nepal are mainly inadequate human resources and poor infrastructure, but this is not the complete picture. The creation of knowledge in Nepal has been shadowed by a conventional knowledge dissemination attitude as found in many developing countries. (8) Being an academic in Nepal, often means working as a mediator. The way of teaching research in Nepalese universities used to be, and often still is, largely theoretical and textbook based. There is a gap between theoretical and practical education. The curricula in undergraduate and post graduate courses in five higher educational institutions - Tribhuvan University, Kathmandu University, Pokhara University, Purbanchal University and BP Koirala Institute of Health Sciences - do not include enough on research methods. A study on research methods coverage in medical and health science curricula in Nepal by Simkhada et al. has highlighted little orientation to research in clinical and lab-based programmes, different weight of research related contents within and across the disciplines, omission of ethical considerations, citation and referencing, systematic review and problems with access to research literature. (9) The theoretical knowledge on research methods is not always translated to practical research work in the field. In addition, established academics hardly generate or disseminate findings from their own work. Nepal's universities do not encourage academics enough to become engaged in research.

There are also people who think the lack of research from academics in low-income countries is because of financial constrains. (10) This is also not the complete picture. Even in low-income countries students and young professionals have managed to establish journals and start their own research. $(11-13)$ It is true that low-income countries cannot invest as much as high-income countries. However, it is

\section{Correspondence:}

${ }^{1}$ Dinesh Neupane

PhD Scholar, Center for Global Health

Department of Public Health

Aarhus University, Denmark.

Email: neupane.dinesh@gmail.com 
often more related to priority setting rather than a complete lack of resources. For example, in Nepal there is no systematic funding where academics can apply for grants. There is a need for more experts and organisations to train the next generation in research and scientific publishing. (14) Ten years ago public health students in Nepal would not know that their teachers had any public health projects. A recent publication did not show a significant change in the situation. (15) In case of sporadic funding, the bureaucratic system is tedious. For example, to initiate a project by a professor, it has to go through the Ministry of Education, then the Vice-chancellor, followed by the Dean, the Campus Chief before it is in the hands of that Professor or the unit. This process is not easy. Many hidden interests from different layers of academia generate barriers to conducting academic research. Furthermore, corruption, a well-known problem in many low-income countries, cannot be underestimated. No wonder the academic sector of Nepal is not attracting highly qualified human resources yet. This is directly related to growth opportunities, salaries and social benefits. Academics in Nepal are poorly paid compared to other professions. (16) When they do not have any research project, they have to rely solely on their basic salary. As a result they are 'forced' to teach in many different places at the same time. These academics often travelling between colleges on a motorbike are commonly known as 'helmet teachers' perpetuating a higher education system, which is 'worthless' in terms of knowledge generation.

It is clear that involvement of academics in research is very important to help promote a research culture in Nepal. This paper explores the way in which academics can be involved in public health research. The key question is: "What can we do to involve the academic community into generation of scientific knowledge and its dissemination?" Focus on the following factors may help to increase knowledge creation in Nepal (and other low-income countries):

1.Create a clear differentiation between teaching and research activities. For example, academics should invest at least $1 / 3$ of their efforts in research. Nowadays, most of the academics of universities in many developing countries are only imitators and not real researchers. If they participate in research they do so outside universities. (10) So, favourable policies to conduct research within universities by academics should be initiated allocating time for both research and teaching.

2.Government should allocate funds to act as research grants that can be used by universities from both public and private sectors. Even a small grant has a potential to yield findings of a high value.

3.Universities and the Government of Nepal should encourage academics to apply for external funding.

4.An academic should be able to administrate received grants within their school or unit, minimizing the complex bureaucratic system.

5.The Government should help establish a reward system at personal as well as institutional level, which attracts the highest possible funding and publishing in high quality academic peer-reviewed journals. The professor who creates patents and publishes in peer-reviewed journals should be awarded by promotion and other career development.

6.Professors should be encouraged to involve their students in significant research areas; especially for the masters and higher degree students. With publications achieved through supervised research professors should receive higher merit points for their promotion. This can act as an incentive for academic development at several levels.

7.Annual show-case seminars and presentations would promote the exchange of ideas within and between institutions. This could also motivate early career researchers, student researchers and other funding bodies for further research.

8.A mechanism has to be established to link researchers with policy makers to focus the research agenda on the most needed areas in Nepal and ensure that relevant research findings are implemented in the future.

9.There is a need to build collaboration with international universities, academics, private sector institutions, libraries and publishers to research capacities of Nepalese universities. This support could be in the form of access to recently published studies, sharing of knowledge between the institutions, and workshops focusing on future possibilities of such collaboration. 


\section{Conclusion}

We are very well aware that not all our suggestions can be acted upon in the short-term. We feel it is very important to create a different attitude towards doing research (and publishing from it) amongst academics in Nepal. Conducting and publishing research in low-income countries is never an easy task as shown by the relatively small number of papers from such countries being published in national and international journals. Academics, the ones who need to promote research among the new generation of public health professionals, are themselves not always aware of the importance of research and publications. The complex bureaucratic system in government-led universities and the profit-oriented attitudes of many private health facilities is very demotivating for the academics. Generating local evidence through research is vital if we want to achieve better health in Nepal. For this, strategic planning is required to improve the research capacity of academia to generate the local evidence needed to improve public health. (17) Moreover, the government should create opportunities for academics to do research, and universities should acknowledge and take credit for research done by their academics.

\section{References}

1.Research Information Network, Joint Information Systems Committee. Communicating knowledge: how and why UK researchers publish and disseminate their findings. London: 2009.

2.van Teijlingen E, Simkhada P, Rizyal A. Submitting a paper to an academic peer-reviewed journal, where to start? Health Renaissance. 2012;10(1): $1-4$.

3.Hanney SR, Gonzalez-Block MA, Buxton MJ, Kogan M. The utilisation of health research in policy-making: concepts, examples and methods of assessment. Health Res Policy Syst. 2003;1(1):2.

4.Siddiqi K, Newell J, Robinson M. Getting evidence intro practice: what works in developing countries. Int J Qual Health Care. 2005;17(5):447-454.

5.Ordonez A. Why is changing donor-driven research agendas so hard? : Politics \& Ideas: a think net; 2013 [cited 2013 8.01.2014]. Available from: http://www. politicsandideas.org/?p=1390.

6.Beasley JW, Starfield B, van Weel C. Global health and primary care research. J Am Board Fam Med. 2007;20(6):518-526.

7.Nchinda TC. Research capacity strengthening in the South. Soc Sci Med. 2002;54(11):1699-1711.

8.Marahatta SB, Dixit H. Students' perception regarding medical education in Nepal. Kathmandu Univ Med J(KUMJ). 2008;6(2):273-283.

9.Simkhada P, van Teijlingen E, Pokharel T, Devkota B, Pathak R. Research methods coverage in medical and health science curricula in Nepal. Nepal Journal of Epidemiology. 2013;3(3):253-259.

10.Sadana R, D'Souza C, Hyder AA, Chowdhury AM. Importance of health research in South Asia. BMJ. 2004;328(7443): 826-830

11.Aslam F, Shakir M, Qayyum MA. Why medical students are crucial to the future of research in South Asia. PLoS Med. 2005;2(11):e322.

12.Editors . Research in Academic Sector: Prospect and Challenges. Health Prospect.2013;12:i-ii.

13.Mishra S, Katuwal S, Mahato N. Triumphs and despair-Journey of Health Prospect from newsletter to peer reviewed journal. Health Prospect. 2013;11:26-7.

14.Magar A.Research and publication culture. J Nepal Health Res Counc. 2012;10(22):i

15. Mahat A, Bezruchka SA, Gonzales V, Connell FA. Assessment of graduate public health education in Nepal and perceived needs of faculty and students. Hum Resour Health. 2013;11(1):16.

16. Himalayan News Service. Professors seek SAARC-level pay. The Himalayan Times. 2011.

17.Simkhada PP, Baral YR, van Teijlingen ER. Health and medical research in Nepal: a bibliometric review. Asia Pac J Public Health. 2010;22(4):492500. 